\title{
Escherichia coli AraJ boosts utilization of arabinose in metabolically engineered cyanobacterium Synechocystis sp. PCC 6803
}

Saurabh Ranade and Qingfang $\mathrm{He}^{*}$

\begin{abstract}
Lignocellulosic biomass can serve as an inexpensive and renewable source of carbon for the biosynthesis of commercially important compounds. L-arabinose is the second most abundant pentose sugar present in the plant materials. Model cyanobacterium Synechocystis sp. PCC 6803 is incapable of catabolism of L-arabinose as a source of carbon and energy. In this study, all the heterologous genes expressed in Synechocystis were derived from Escherichia coli K-12. Initially we constructed four Synechocystis strains that expressed AraBAD enzymes involved in L-arabinose catabolism, either in combination with or without one of the three arabinose transporters, AraE, AraFGH or AraJ. Among the recombinants, the strain possessing AraJ transporter was observed to be the most efficient in terms of dry biomass production and L-arabinose consumption. Later, an additional strain was generated by the expression of AraJ in the AraE-possessing strain. The resultant strain was shown to be advantageous over its parent. This study demonstrates that AraJ, a protein with hitherto unknown function plays a role in the uptake of L-arabinose to boost its catabolism in the transgenic Synechocystis strains. The work also contributes to the current knowledge regarding metabolic engineering of cyanobacteria for the utilization of pentose sugars.
\end{abstract}

Keywords: Cyanobacteria, Metabolic engineering, Synechocystis, Arabinose transporter, AraJ, AraBAD

\section{Key points}

Synechocystis strains were engineered to transport and catabolize L-arabinose.

$\mathrm{L}$-arabinose transport took place even in the absence of heterologous transporters.

Expression of putative transporter gene araJ showed the most impressive results.

\section{Introduction}

Biomass is an abundant and renewable raw material that can be converted into a number of useful products, transportation fuels and direct energy (Ragauskas et al. 2006). Hemicelluloses which comprise of heterogeneous polymers of pentoses, hexoses, and organic acids represent

*Correspondence: qfhe@ualr.edu

Department of Biology, University of Arkansas at Little Rock, 2801 South University Avenue, Little Rock, AR 72204, USA about $20-35 \%$ of the total lignocellulosic biomass (Saha 2003). Xylose stands out as the predominant pentose sugar in the hardwood hemicelluloses. However, L-arabinose is one of the major pentose sugars in the leaves of grass and other herbaceous species, and also in agricultural residues such as rapeseed meal, corn fibre, barley straw, rice straw, wheat bran etc. (Mohagheghi et al. 2002; Schädel et al. 2010; Gìrio et al. 2010; Lomascolo et al. 2012). In arabinose-utilizing bacteria, $\mathrm{L}$-arabinose is transported across the cell membrane by means of specialized transporter proteins. In the first step after transportation, L-arabinose is isomerized to L-ribulose by the action of AraA (L-arabinose isomerase). L-ribulose is irreversibly phosphorylated by AraB (L-ribulokinase) to form L-ribulose-5-phosphate (hereafter L-Ru5P). In the last step, L-Ru5P is converted by AraD (L-ribulose-5-phosphate 4-epimerase) to a pentose phosphate 
pathway intermediate, D-xylulose-5-phosphate (hereafter D-Xu5P) (Schleif 2010; Caspi et al. 2018) (Fig. 1).

Unlike glucose, pentose sugars are less susceptible to bacterial action. Among the few bacterial species that possess the natural ability to utilize pentose sugars, productivity and yield remain low owing to a variety of issues such as insufficient transport, catabolite repression, and cellular redox imbalance in pentose metabolism. Hence, transformation of industrial strains with heterologous pentose pathway-specific genes has been a popular strategy to enable the strains to grow on lignocellulosic hydrolysates (Jojima et al. 2010). Cyanobacterium, Synechocystis sp. PCC 6803 (hereafter Synechocystis) is one of the most extensively studied primary phototrophs. It is able to grow under autotrophic, mixotrophic, and heterotrophic conditions, can integrate foreign DNA at a high frequency, and holds a proven record as a host strain for the synthesis of biofuels, health related compounds, and commodity chemicals (Yu et al. 2013).

Several groups have engineered bacterial strains, either to enable them to utilize L-arabinose or to improve their efficiency to utilize the wood sugar. In an early study, arabinose utilization genes $\operatorname{araBAD}$ and pentose phosphate pathway genes talB-tktA from Escherichia coli were introduced into Zymomonas mobilis ATCC 39676 under the control of GAP and ENO promoters, respectively, in order to obtain a co-fermenting strain which was able to convert L-arabinose into ethanol at 98\% maximum theoretical yield (Deanda et al. 1996). In the study by Mohagheghi et al. (2002), E. coli genes involved

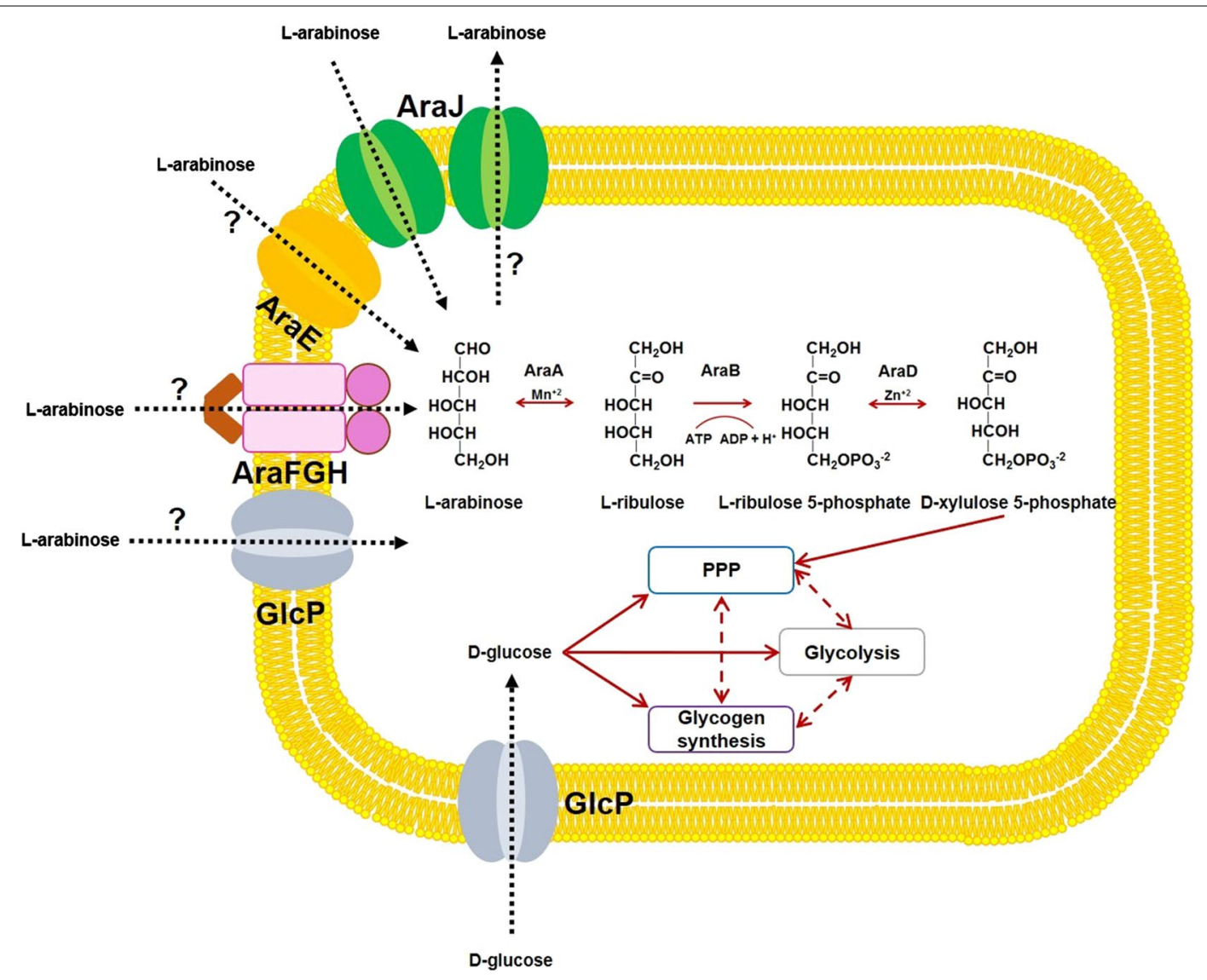

Fig. 1 Metabolic scheme for engineering Synechocystis strains. L-arabinose may enter the transformant strains by means of native transporter/s such as GlcP and heterologous transporters such as AraE, AraFGH and AraJ. Direction of entry and exit of sugars (established, indicated in this study and putative) is shown using dotted arrows. L-arabinose is converted to L-ribulose by L-arabinose isomerase (AraA) in the presence of manganese ions $\left(\mathrm{Mn}^{+2}\right.$ ). L-ribulose is phosphorylated to L-ribulose 5-phosphate (L-Ru5P) by the action of L-ribulokinase (AraB). L-Ru5P is converted by L-ribulose 5-phosphate 4-epimerase (AraD) in the presence of zinc ions $\left(\mathrm{Zn}^{+2}\right)$ to $\mathrm{D}$-xylulose 5-phosphate (D-Xu5P), which enters the pentose phosphate pathway (PPP). Bidirectional arrows indicate a reversible reaction or connections between metabolic pathways through intermediates. Unidirectional arrows indicate a non-reversible reaction or the ability of a sugar or an intermediate to either enter or exit a pathway. Dashed arrows indicate the involvement of one or more intermediates. Question marks (?) indicate putative transport of L-arabinose. Other abbreviations: ADP, adenosine diphosphate; ATP, adenosine triphosphate 
in arabinose, xylose, and pentose phosphate pathway were stably integrated into the genome of $Z$. mobilis to obtain a strain which was able co-ferment xylose, arabinose, and glucose into ethanol at $84 \%$ process yield. Similarly, E. coli araBAD genes were expressed under lac promoter in Corynebacterium glutamicum $\mathrm{R}$ to generate a strain which was able to produce organic acids from $\mathrm{L}$-arabinose even in the presence of glucose (Kawaguchi et al. 2008). The work by Kawaguchi et al. (2008) was further enhanced by the introduction of trc promotercontrolled pentose transporter gene araE from C. glutamicum ATCC 31831 to the parental strain harbouring $\operatorname{araBAD}$ genes. The resultant strain showed a 2.8 -fold increase in the $\mathrm{L}$-arabinose consumption rates under oxygen-deprived conditions. The strain could also grow aerobically on L-arabinose at lower concentrations in comparison with the parental strain (Sasaki et al. 2009). In one of the first reported works involving cyanobacteria, Cao et al. (2017) constructed an L-arabinose-based inducible module comprising of $E$. coli araBAD promoter in Synechococcus elongatus PCC 7942. Expression of E. coli ara $E$ under $t r c$ promoter failed to improve arabinose transport. To alleviate inhibitory effects of L-arabinose in the cells, E. coli araBAD genes were expressed under J23119, a constitutive promoter. After 10 days of cultivation, the consumption of $\mathrm{L}$-arabinose was estimated at $0.40 \mathrm{~g} / \mathrm{L}$ in diurnal and $0.84 \mathrm{~g} / \mathrm{L}$ in continuous light condition, where the corresponding $\mathrm{O} \mathrm{D}_{730}$ values were $\sim 1.3$ and $\sim 2.0$, respectively. In addition to the bacterial strains, several arabinose-utilizing yeast strains have been generated by the introduction of transporter and catabolic genes of bacterial or fungal origin (Young et al. 2010).

In this study, we compared the biomass yield and L-arabinose uptake of four recombinant Synechocystis strains heterologously expressing arabinose-specific catabolic genes $\operatorname{araBAD}$ without or with one of three arabinose transporters (AraE, AraFGH, AraJ) under consideration. AraE (proton symporter) and AraFGH are well characterized members of the Major Facilitator Superfamily (hereafter MFS) class and ATP Binding Cassette (hereafter $A B C$ ) class of transporter proteins, respectively (Jojima et al. 2010). In E. coli, the exact function of AraJ has remained unknown (Reeder and Schleif 1991; Fritz et al. 2014). However, in terms of homology, AraJ has been grouped with multidrug efflux proteins of the MFS, as a member of drug $\mathrm{H}^{+}$antiporter (DHA1) family (Bost et al. 1999; Kanehisa et al. 2016). All the arabinose-specific genes used in this study were sourced from $E$. coli $\mathrm{K}-12$. We further showed that the expression of AraJ in the strain possessing AraE improved arabinose consumption and alleviated stress. Earlier, we had constructed Synechocystis strains with varying abilities to utilize
D-xylose and showed that xylose consumption could be enhanced by the expression of efficient transporters (Ranade et al. 2015). Here, we report the generation of recombinant Synechocystis strains with various abilities to utilize L-arabinose. Our data suggests that AraJ, a poorly characterized MFS protein, is involved in the uptake of L-arabinose when expressed in Synechocystis.

\section{Materials and methods}

\section{Bacterial strains and growth conditions}

E. coli strain K-12 was used as the source organism for amplification of arabinose-specific transporter and catabolic genes, while E. coli TOP10 (Thermo Fisher Scientific) was used for cloning and plasmid construction steps. The strains were grown at $37^{\circ} \mathrm{C}$ on solid LB medium or in liquid LB medium with shaking $(220 \mathrm{rpm})$ in the presence of appropriate antibiotic, if necessary. Antibiotic concentrations used for selection were- ampicillin: $100 \mu \mathrm{g} / \mathrm{mL}$, kanamycin: $25 \mu \mathrm{g} / \mathrm{mL}$, erythromycin: $200 \mu \mathrm{g} / \mathrm{mL}$, and spectinomycin: $50 \mu \mathrm{g} / \mathrm{mL}$. The antibiotics were purchased from Thermo Fisher Scientific.

\section{Plasmid construction}

To construct the transformation vectors designed to insert arabinose transporter genes into Synechocystis wild-type strain (hereafter WT), kanamycin resistance cassette, upstream and downstream regions of a neutral site (near slr1285, denoted as neutral site 1 ), $\mathrm{a} \sim 0.4 \mathrm{~kb}$ region encompassing the $p s b A 2$ promoter (denoted as $p s b A 2$ promoter) and a $\sim 0.5 \mathrm{~kb} 5 \mathrm{ST} 1 \mathrm{~T} 2$ double terminator region were inserted into pBluescript II SK+ (Stratagene) as described (Ranade et al. 2015). The arabinose transporter genes araE, araFGH, and araJ were amplified from genomic DNA isolated from E. coli K-12 strain. The primers used to amplify the transporter genes were as follows:

5'-ACTCGAATTCATGGTTAC TATCAATACGGA ATC- $3^{\prime}$ (forward primer) and 5'-ACTCCTGCAGTC AGACGCCGATATTTCTC-3' (reverse primer) for araE;

5'-ACTCGAATTCATGCACAAATTTACTAAAGC CCTG-3' (forward primer) and 5'-ACTCCTGCAGTC AGACAGTGCGTTTCGCTTTTTG-3' (reverse primer) for $\operatorname{araFGH}$;

5'-ACTCGAATTCATGAAAAAAGTCATTTTATC TTTGGCTC- $3^{\prime}$ (forward primer) and $5^{\prime}$-ACTCCTGCA GCTACCCCAGTGGTTTCGCCAG-3' (reverse primer) for araJ.

The amplicons were inserted between EcoRI-PstI sites of the plasmid to generate three individual plasmids. Note that, in the case of araFGH gene set, only the region from the start codon of araF to the end codon of araG was amplified; no other regulatory elements from the $E$. coli araFGH operon were included. 
To construct the plasmid designed to insert arabinose-specific catabolic genes into Synechocystis strains possessing exogenous arabinose transporters and in the WT strain, erythromycin resistance cassette was amplified from plasmid pTSC (Yan et al. 2008) using the following primers:

5'-ACTCGGATCCGAGCTCGTGCTATAATTATA CTAATTTTATAAG- $3^{\prime}$ (forward primer) and $5^{\prime}$-ACT CGGATCCATCGATTCACAAAAAATAGGCACACG $-3^{\prime}$ (reverse primer). The amplicon was inserted into pBluescript II SK+ plasmid at BamHI site. The neutral site sequence (near slr0646; hereafter referred to as neutral site 2) (Gonzalez-Esquer and Vermaas 2013) was amplified from genomic DNA isolated from Synechocystis as upstream and downstream regions using the following primers:

5'-ACTCGGTACCTTCTGTAAGCACTTCGATCG TTAG-3' (forward primer) and $5^{\prime}$-ACTCCTCGACAT GGGGATCAGCGCTAAATGC-3' (reverse primer) for the upstream region, and $5^{\prime}$-ACTCACTAGTAAGCC CATTTACGTCGTGTTGGTC-3' (forward primer) and $5^{\prime}$-ACTCCCGCGGCCAACGGTTCCAGGTGA CTATC-3' (reverse primer) for the downstream region. The upstream and downstream fragments were inserted between KpnI-XhoI and SpeI-SacII sites of the plasmid, respectively. The $p s b A 2$ promoter and 5ST1T2 double terminator were amplified and cloned into the plasmid as described (Ranade et al. 2015). In the last step, the arabinose catabolic gene set $\operatorname{araBAD}$ was amplified from genomic DNA isolated from the $E$. coli $\mathrm{K}-12$ strain using the following primers:

5'-ACTCGAATTCATGGCGATTGCAATTGGCCT C-3' (forward primer) and

$5^{\prime}$-ACTCCCTGCAGGTTACTGCCCGTAATATGC CTTC-3' (reverse primer). The amplicon was digested at the EcoRI-Sbfl restriction sites present at its ends and inserted between the EcoRI-PstI sites of the plasmid. Similar to $\operatorname{araFGH}$, in the case of $\operatorname{araBAD}$ gene set, only the region from the start codon of araB to the end codon of $a r a D$ was amplified; no other regulatory elements from the E. coli araBAD operon were included.

To construct the plasmid vector for the insertion of araJ into the engineered strain possessing araE and $\operatorname{ara} B A D$, spectinomycin resistance cassette, upstream and downstream regions of a neutral site (slr1608, denoted as neutral site 3), $p s b A 2$ promoter and 5ST1T2 double terminator region were inserted into pBluescript II SK+ (Stratagene) as described (Ranade et al. 2015). In the last step, araJ was amplified from E. coli K-12 genomic DNA using the primer pair described above, and was inserted between EcoRI-PstI sites of the plasmid.

\section{Transformation and segregation of Synechocystis strains} Synechocystis strains were grown at $30{ }^{\circ} \mathrm{C}$ on solid BG-11 and in liquid BG-11 medium at $50-60 \mu \mathrm{E} \mathrm{m} \mathrm{m}^{-2}$ light intensity, with constant shaking $(200 \mathrm{rpm})$. When $\mathrm{OD}_{730}$ reached $\sim 0.7-0.8$, the transformations were carried out as described (Porter 1988). Upon confirmation of the presence of heterologous genes by PCR analyses, cells were streaked on BG-11 agar plates containing successively higher antibiotic concentrations. PCR checks were performed to ensure complete segregation of the transformants.

\section{Reverse transcription PCR}

Total RNA was isolated from cultures of Synechocystis strains at $\mathrm{OD}_{730} \sim 0.7$ as previously described (Mohamed and Jansson 1989). Turbo DNA-free Kit (Thermo Fisher Scientific) was used to remove carried over genomic DNA per manufacturer's instructions. The reverse transcription reactions were carried out using Superscript III enzyme (Life Technologies) and random hexamers (New England BioLabs). The cDNA molecules were then used as templates for PCR, employing the same set of primers used to amplify the heterologous genes. As negative controls, DNase-treated RNA molecules were used as templates, and the same primer pairs were employed. petA (sll1317) was used as the positive control as described (Ranade et al. 2015). For longer templates such as $\operatorname{araFGH}$ and $\operatorname{araBAD}$ gene sets, the SuperScript OneStep RT-PCR system for long templates (Thermo Fisher Scientific) was used per manufacturer's instructions. PCR products were analyzed on $0.8 \%$ agarose gel.

\section{Biomass measurement}

Growth exhibited by Synechocystis strains was measured in terms DW as described (Davies et al. 2014). Biomass estimation studies were performed concurrently with the enzymatic assays. The cultures of Synechocystis strains were initiated in $110 \mathrm{~mL}$ BG-11 liquid medium at $30{ }^{\circ} \mathrm{C}$ under shaking conditions (200 rpm), with the initial $\mathrm{OD}_{730}$ of 0.05 . The cultures were provided with: for autotrophy, $\sim 60 \mu \mathrm{E} \mathrm{m}^{-2} \mathrm{~s}^{-1}$ light; for mixotrophy, $20 \mathrm{mM}$ L-arabinose $(3.00 \mathrm{~g} / \mathrm{L})$ or $20 \mathrm{mM}$ D-glucose $(3.60 \mathrm{~g} / \mathrm{L})$ or $10 \mathrm{mM}$ each of L-arabinose $(1.50 \mathrm{~g} / \mathrm{L})$ and $\mathrm{D}$-glucose $(1.80 \mathrm{~g} / \mathrm{L})$ along with $\sim 60 \mu \mathrm{E} \mathrm{m}^{-2} \mathrm{~s}^{-1}$ light. Biomass values were estimated at 6 -h intervals for the first 3 days followed by 24 -h intervals for the next 4 days.

\section{Enzymatic assays for measurement of sugar uptake}

Enzymatic uptake assays were performed for the cultures grown only under mixotrophy. During the assays, $1 \mathrm{~mL}$ cultures were collected at the same time intervals specified for biomass measurements. The cultures were immediately filtered using $0.45 \mu \mathrm{m}$ pore size $13 \mathrm{~mm}$ nylon 
membrane syringe filters (Fisher Scientific) to obtain cellfree media.

The amount of $\mathrm{L}$-arabinose present in the filtered media was measured using L-Arabinose/D-Galactose Assay Kit (Megazyme) per manufacturer's instructions. Sequential action of galactose mutarotase and $\beta$-galactose dehydrogenase generates NADH molecules. The amount of $\mathrm{NADH}$ is stoichiometric with that of L-arabinose which was calculated from the difference in $\mathrm{OD}_{340}$ values before and after the $\beta$-galactose dehydrogenase action.

The amount of D-glucose present in the filtered media was measured using D-Glucose Assay Kit-GOPOD Format (Megazyme) per manufacturer's instructions. Action of glucose oxidase and peroxidase generates quinoneimine dye. The amount of quinoneimine formed is stoichiometric with that of D-glucose. The amount of D-glucose in the cell-free media was calculated from $\mathrm{OD}_{510}$ values obtained for the samples, in reference to the $\mathrm{OD}_{510}$ value read for a glucose standard.

\section{Results}

Comparative performance studies of Synechocystis strains Construction of recombinant strains of Synechocystis

For the purpose of comparative performance studies, Synechocystis strains possessing arabinose transporter and catabolic genes were developed from the WT strain in two distinct rounds of transformation by homologous double recombination. In the first round, three recombinant strains possessing one of the three transporter genes, araE or $\operatorname{araFGH}$ or araJ of E. coli $\mathrm{K}-12$ origin were generated. The strains were named A-Tr1, A-Tr2 and A-Tr3, respectively, and collectively referred to as A-Tr. In the subsequent round of transformation, four recombinant strains were generated by inserting the $\operatorname{araBAD}$ gene set of $E$. coli K-12 origin into the three strains generated in the first round of transformation and the WT strain. The recombinant strains were named A-Ut1,
A-Ut2, A-Ut3 and A-Ut4, respectively, and collectively referred to as A-Ut (Table 1). In this study, araFGH and $\operatorname{araBAD}$ will hereafter be referred to as araFGH and $\operatorname{ara} B A D$ gene sets, respectively. araFGH gene set includes the region from the start codon of $\operatorname{araF}$ gene to the end codon of $a r a H$ gene. Similarly, araBAD gene set includes the region from the start codon of $\operatorname{ara} B$ gene to the end codon of araD gene.

\section{Verification of genetic transformation and segregation of the recombinants}

The heterologous genes were introduced into the neutral sites of Synechocystis genome by homologous recombination. After each round of transformation, the presence of heterologous gene insert was verified. Upon verification of transformation, the recombinant strains were segregated in the presence of increasing antibiotic pressure. The segregated strains were used in the next round of transformation and for further work.

To verify the presence of heterologous transporter genes in the strains generated after the first round of transformation, i.e., A-Tr1, A-Tr2 and A-Tr3, the same pairs of primers used to amplify the respective genes from E. coli K-12 genomic DNA were used. Primers A1/ $\mathrm{A} 2$ for $\operatorname{araE}, \mathrm{B} 1 / \mathrm{B} 2$ for araFGH and $\mathrm{C} 1 / \mathrm{C} 2$ for araJ generated products of approximately $1.42 \mathrm{~kb}, 3.58 \mathrm{~kb}$ and $1.18 \mathrm{~kb}$ in length, respectively (Figs. $2 \mathrm{a}$ and $3 \mathrm{a}$ ). To verify segregation of the recombinants, the forward primer used to amplify the upstream region and the reverse primer used to amplify the downstream region of neutral site 1 were used (D1/D2) (Fig. 2a). Extension times in the PCR cycles were set specifically to amplify the uninterrupted neutral site 1. PCR amplifications produced $\mathrm{a} \sim 1.20 \mathrm{~kb}$ band representing neutral site 1 only in the WT strain maintained as the positive control. The results showed the absence of uninterrupted neutral site 1 and hence complete segregation of the A-Tr strains (Fig. 3b).

Table 1 Synechocystis strains used in this study

\begin{tabular}{|c|c|c|}
\hline Strain & Genotype & Description \\
\hline WT & Wild-type Synechocystis sp. 6803 & Wild-type genomic sequence \\
\hline$A-\operatorname{Tr} 1$ & $\operatorname{araE}-\triangle \mathrm{Neu} 1$ & araE inserted at neutral site 1 (near s/r1285) \\
\hline$A-\operatorname{Tr} 2$ & $\operatorname{araFGH}-\triangle$ Neu 1 & araFGH gene set inserted at neutral site 1 (near s/r1285) \\
\hline$A-\operatorname{Tr} 3$ & araJ- $\triangle$ Neu 1 & araJ inserted at neutral site 1 (near s/r1285) \\
\hline A-Ut1 & araE- $\triangle$ Neu $1::$ araBAD- $\triangle$ Neu 2 & araE inserted at neutral site 1 (near s/r1285), araBAD gene set inserted at neutral site 2 (near s/r0646) \\
\hline $\mathrm{A}-U \mathrm{t} 2$ & araFGH- $\triangle$ Neu 1::araBAD- $\triangle$ Neu 2 & $\begin{array}{l}\text { araFGH gene set inserted at neutral site } 1 \text { (near s/r1285), araBAD gene set inserted at neutral site } 2 \\
\text { (near s/r0646) }\end{array}$ \\
\hline A-Ut3 & araJ- $\triangle$ Neu $1:: a r a B A D-\triangle N e u 2$ & araJ inserted at neutral site 1 (near s/r1285), araBAD gene set inserted at neutral site 2 (near s/r0646) \\
\hline A-Ut4 & $\operatorname{araBAD}-\triangle \mathrm{Neu} 2$ & araBAD gene set inserted at neutral site 2 (near s/r0646) \\
\hline A-Ut5 & araE- $\triangle$ Neu 1::araBAD- $\triangle$ Neu 2::araJ- $\triangle$ Neu 3 & $\begin{array}{l}\text { araE inserted at neutral site } 1 \text { (near s/r1285), araBAD gene set inserted at neutral site } 2 \text { (near s/r0646), } \\
\text { araJ inserted at neutral site } 3 \text { (s/r1608) }\end{array}$ \\
\hline
\end{tabular}




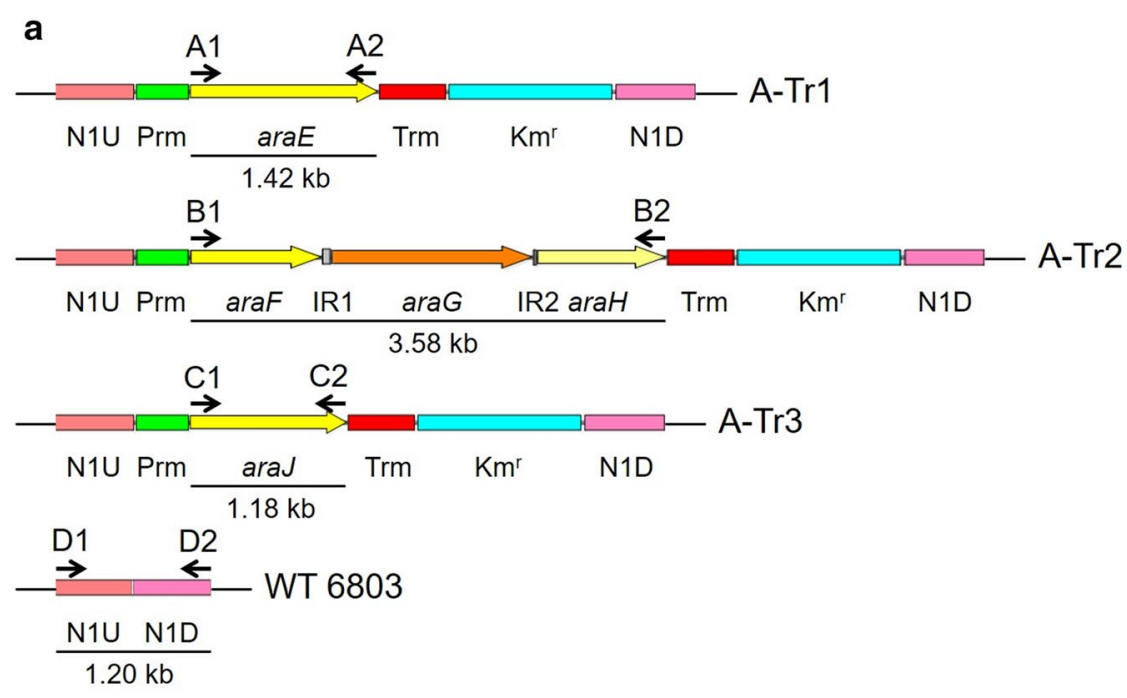

b
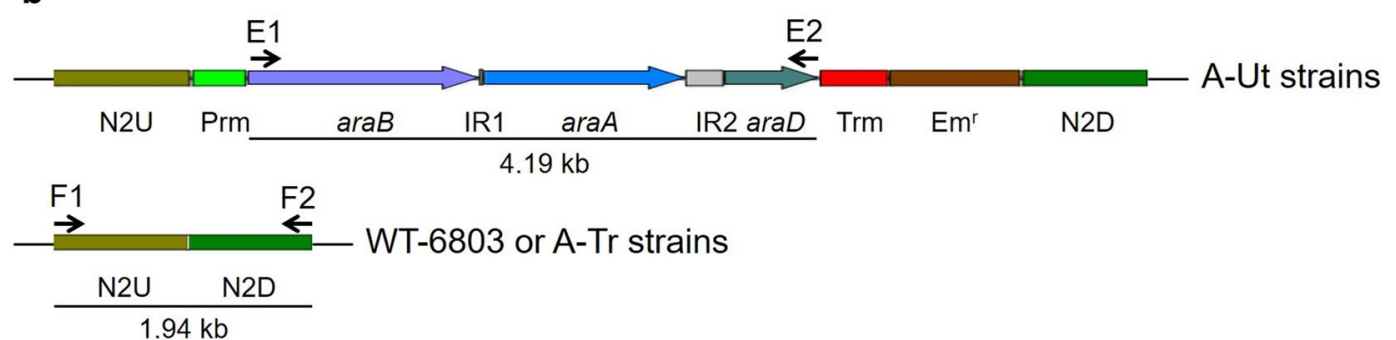

Fig. 2 Transformation of Synechocystis strains. All transgenes used in the study were expressed under the control of the psbA2 promoter (Prm) and 5ST1T2 terminator (Trm). Intergenic regions (IR) present between individual genes in the gene sets are represented as grey boxes. Numbered letters and arrows represent the primer pairs, and the direction of the amplifications, respectively. a Genes encoding the arabinose transporters were inserted into neutral site 1 in the Synechocystis WT genome using upstream (N1UP) and downstream (N1DW) regions for homologous recombination. The kanamycin resistance cassette $\left(\mathrm{Km}^{r}\right)$ was used for the selection and segregation of the transformants. $\mathbf{b}$ The araBAD gene set, encoding enzymes that funnel arabinose into the pentose phosphate pathway, was inserted into neutral site 2 in the genomes of Synechocystis strains carrying one of the three arabinose transporter genes and the WT strain using upstream (N2UP) and downstream (N2DW) regions for homologous recombination. The erythromycin resistance cassette $\left(\mathrm{Em}^{\mathrm{r}}\right)$ was used for the selection and segregation of the transformants

To test for the presence of catabolic gene set $\operatorname{araBAD}$ in the strains obtained after the second round of transformation, i.e., A-Ut1, A-Ut2, A-Ut3 and A-Ut4, the same pair of primers used to amplify araBAD from $E$. coli K-12 genomic DNA was used. Primers E1/E2 for araBAD gene set generated products of approximately $4.19 \mathrm{~kb}$ in length (Figs. $2 \mathrm{~b}$ and $3 \mathrm{c}$ ). To verify segregation, the forward primer used to amplify the upstream region and the reverse primer used to amplify the downstream region of neutral site 2 were used (F1/ F2) (Fig. 2b). Extension times in the PCRs were set to amplify the uninterrupted neutral site 2. PCR amplifications produced $\mathrm{a} \sim 1.94 \mathrm{~kb}$ band representing neutral site 2 only in the WT strain maintained as the positive control. The results indicated the absence of uninterrupted neutral site 2 and hence complete segregation of the A-Ut strains (Fig. 3d).

\section{Verification of transcription of heterologous genes}

After verification of segregation, transcription of the arabinose-specific heterologous genes in the A-Tr and A- Ut strains was examined by RT-PCR. As the positive control, expression of petA (sll1317) coding for apocytochrome $f$, a core subunit of cytochrome $b_{f} f$ complex was tested. As the negative control, DNase-treated RNA samples obtained from each strain were tested to ensure the absence of any leftover DNA in the RNA samples. In the presence of cDNA templates obtained from the respective strains, primers A1/A2 for araE, B1/B2 for araFGH, $\mathrm{C} 1 / \mathrm{C} 2$ for araJ and E1/E2 for araBAD generated products of expected sizes. In negative control reactions, the aforementioned primer pairs failed to generate any product. A $\sim 0.98-\mathrm{kb}$ band representing petA was obtained for positive controls in all the transformants (Figs. 2a, b and $3 e, f)$. The results indicate successful transcription of all 


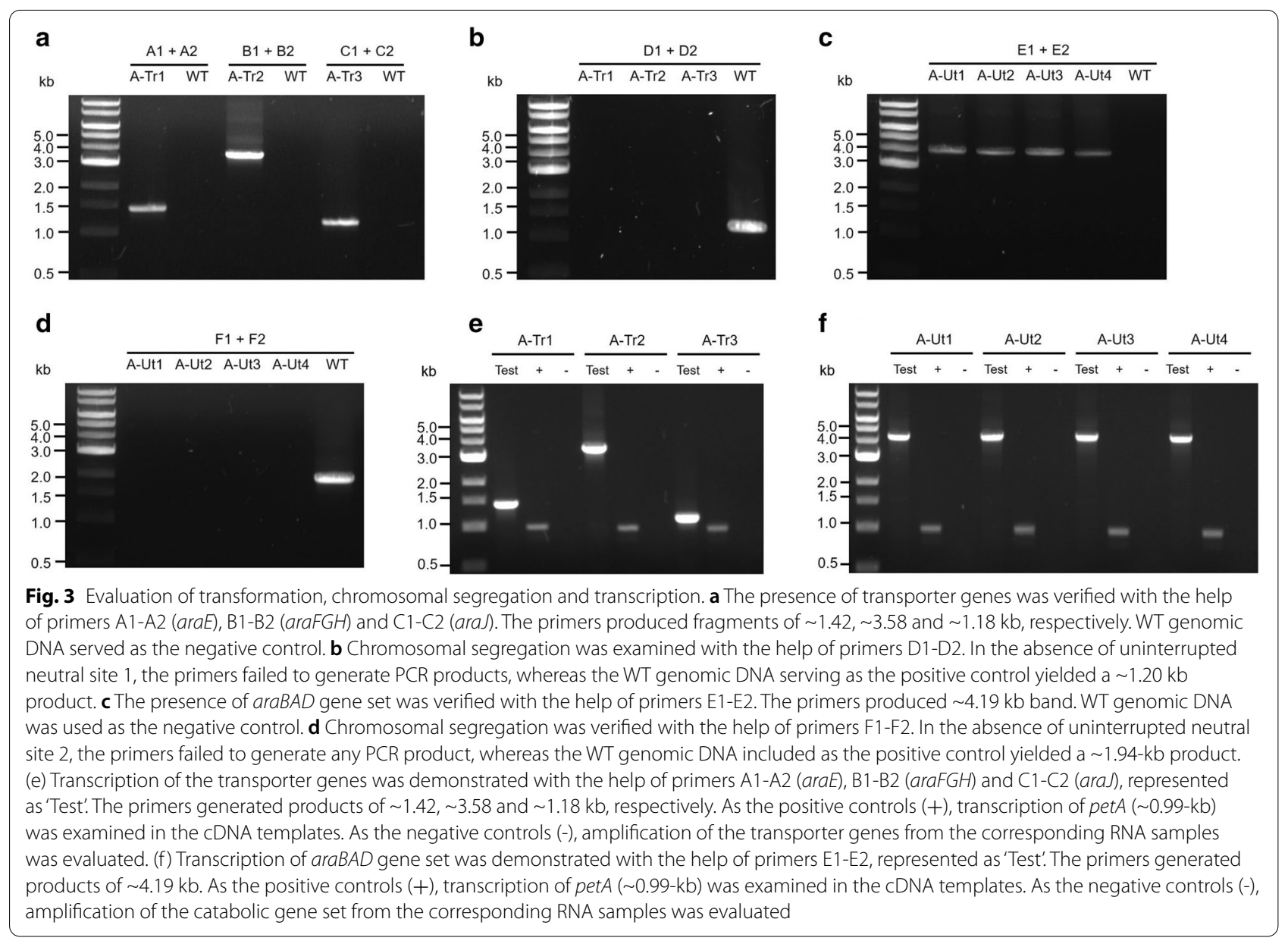

the heterologous genes/ gene sets and verify the quality of the RNA samples.

\section{Study of biomass accumulation by the recombinants}

To study and compare the growth patterns exhibited by the WT, A-Tr and A-Ut strains, they were cultured under various conditions. For biomass measurements, cells were collected at 6-h intervals for the first 3 days and then at 24-h intervals for the next 4 days. Under autotrophy, biomass yields were similar for all the strains. Under mixotrophy with $20 \mathrm{mM}$ glucose (hereafter mixotrophyglucose), biomass yields were observed to be similar for all the strains except for the AraJ-possessing A-Tr3 and A-Ut3 strains. A-Tr3 and A-Ut3 strains showed a degree of growth impairment in the presence of $20 \mathrm{mM}$ glucose (Additional File 1: Figure S1a-h).

Under mixotrophy with $20 \mathrm{mM}$ arabinose (hereafter mixotrophy-arabinose), the WT and the A-Tr strains showed biomass yields similar to those obtained under autotrophy, indicating the inability of the strains to utilize arabinose. However, the A-Ut strains showed greater dry weight (hereafter DW) yields under the mixotrophy-arabinose condition than under autotrophy. Biomass accumulation results demonstrate that all the A-Ut strains carrying the catabolic gene set were able to utilize arabinose. Under the mixotrophy-arabinose condition, at the 7th day of culture, the biomass reached by the A-Ut1, A-Ut2, A-Ut3 and A-Ut4 strains was 31\%, $43 \%, 112 \%$, and $\sim 50 \%$ greater than the average biomass for the four strains under autotrophy. In the presence of arabinose, AraJ-possessing A-Ut3 strain showed higher biomass values than the other A-Ut strains at each time point. At the 7th day of culture, A-Ut3 showed 38\% greater biomass than the A-Ut4 strain, which lacked any heterologous transporter (Fig. 4a, b; Additional File 1: Figure S1b, d, f, h).

To further examine the ability of the arabinose-consuming A-Ut strains to grow in the presence of arabinose and glucose, we cultured the strains under mixotrophy, in the presence of $10 \mathrm{mM}$ each of arabinose and glucose (hereafter mixotrophy-mixed sugar). Under the mixotrophy-mixed sugar condition, at the 7th day of culture, the biomass reached by the arabinose-consuming strains, A-Ut1, A-Ut2, A-Ut3 and A-Ut4 was 124\%, 130\%, 


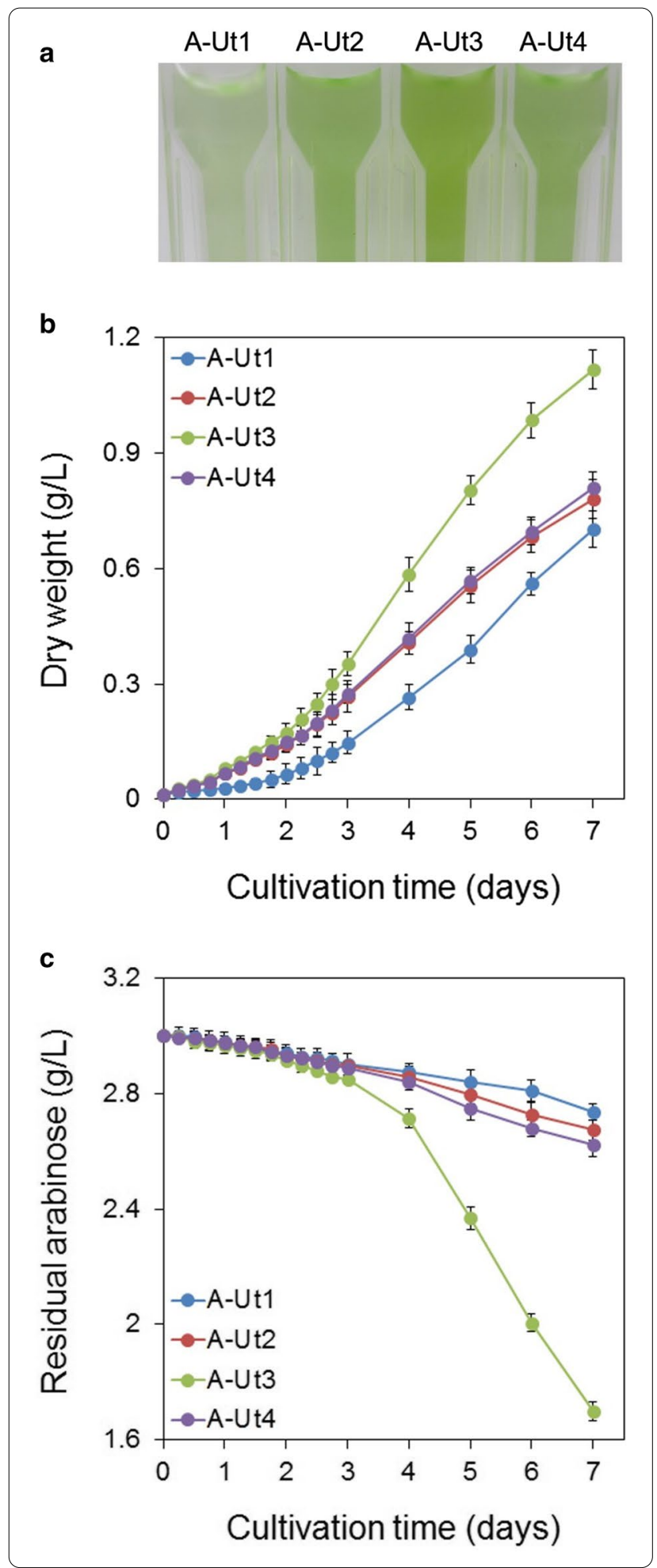

Fig. 4 Growth and arabinose consumption under mixotrophy in the presence of $20 \mathrm{mM}$ arabinose. Synechocystis strains A-Ut1, A-Ut2, A-Ut3 and A-Ut4 were grown in the presence of $20 \mathrm{mM}(3.0026 \mathrm{~g} / \mathrm{L})$ L-arabinose. a Photograph depicting differential growth shown by the transformant strains at the end of the fourth day of culture. $\mathbf{b}$ Dry biomass and $\mathbf{c}$ Residual arabinose measured in the cultures of the transformant strains. Data represented in graphs were collected from three biological replicates and presented as means \pm standard deviations

$215 \%$, and $\sim 136 \%$ greater than the average biomass for the four strains accumulated under autotrophy. Similar to the mixotrophy-arabinose condition, the A-Ut3 strain showed higher biomass values than the other A-Ut strains at each time point tested. At the end of the last day of culture, A-Ut3 showed $\sim 31 \%$ greater biomass than the A-Ut4 strain. Under mixotrophy-arabinose as well as mixotrophy-mixed sugar condition, the AraFGHpossessing A-Ut2 strain showed DW values similar to those shown by the A-Ut4 strain. On the other hand, the AraE-possessing A-Ut1 strain showed marginally lower DW values than those observed for the A-Ut4 strain at all time points. In the presence of arabinose and glucose, the A-Ut strains did not show two distinct growth phases (Figs. 4a, b and 5a, b; Additional File 1: Figure S1b, d, f, h).

\section{Sugar uptake assays}

Sugar uptake measurements were made alongside the biomass estimations under mixotrophy-arabinose and mixotrophy-mixed sugar conditions. Under the mixotrophy-arabinose condition, the WT and A-Tr strains that lacked the arabinose-specific catabolic gene set araBAD showed no change in the amount of arabinose present in the medium, indicating their inability to utilize the sugar (Additional File 1: Figure S1a, c, e, g). The A-Ut strains which harbored the araBAD gene set showed varying degrees of arabinose consumption. Under the mixotrophy-arabinose condition, the AraJ-possessing A-Ut3 strain showed arabinose uptake greater than those exhibited by the A-Ut1, A-Ut2 and A-Ut4 strains. At the 7th day of culture, the A-Ut3 strain showed 243\% greater arabinose uptake than the A-Ut4 strain (Fig. 4c, Additional File 1: S1b, d, f, h). 
a
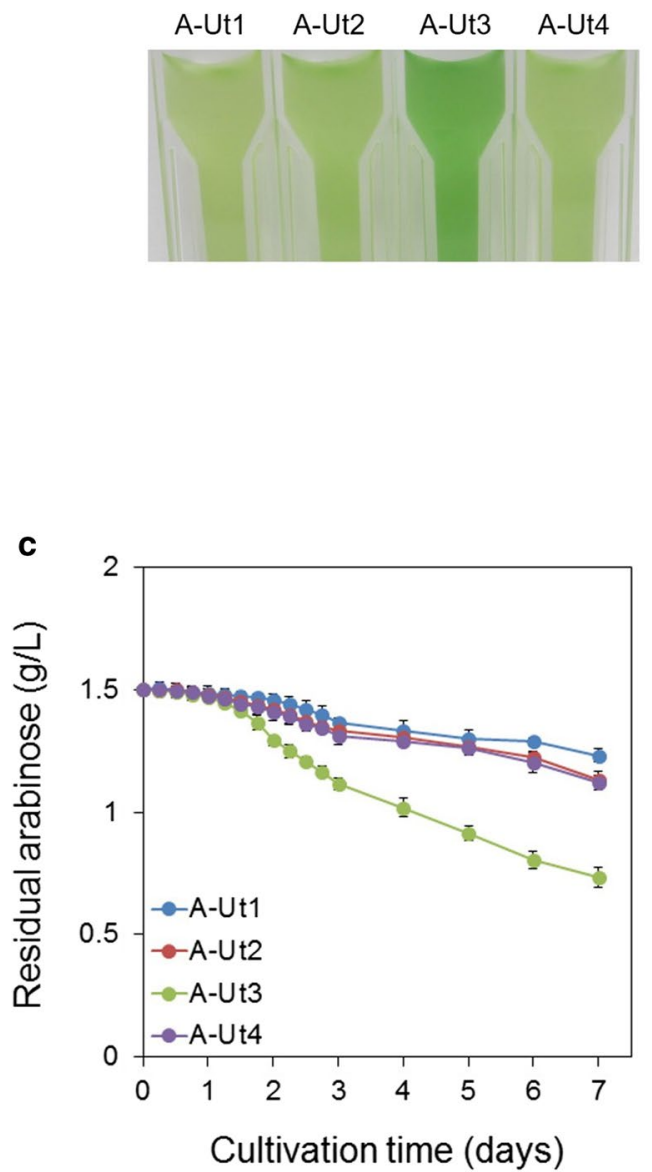
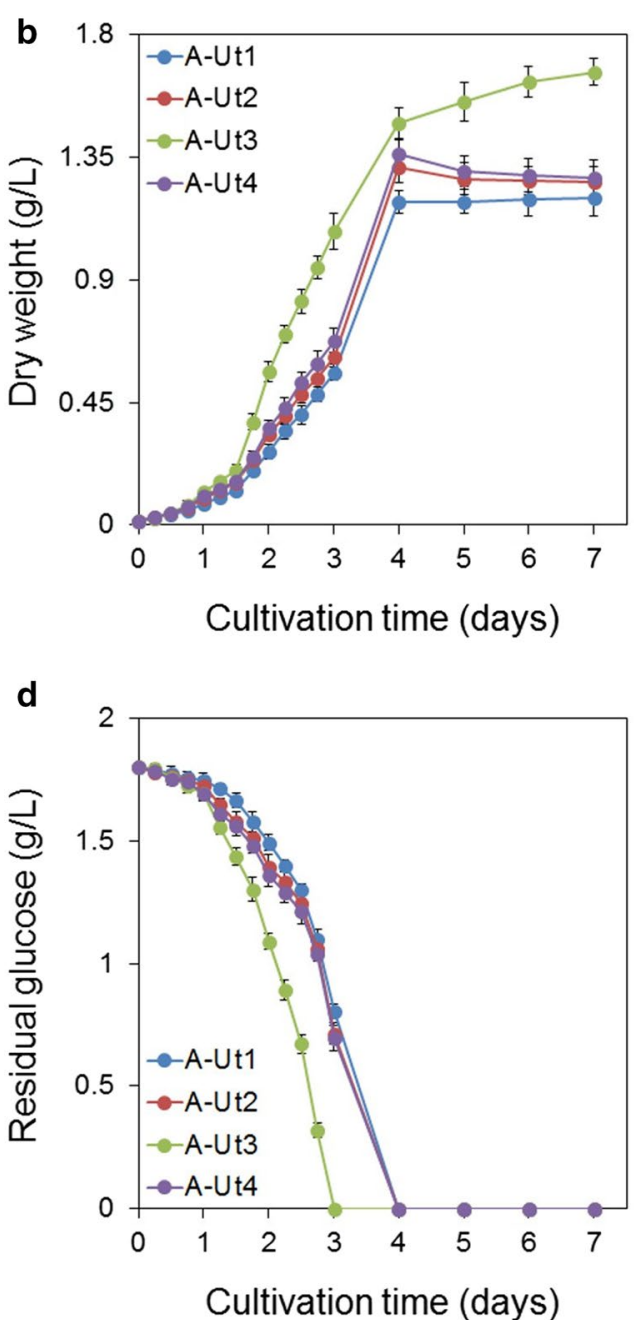

Fig. 5 Growth and sugar consumption in the presence of $10 \mathrm{mM}$ arabinose and glucose. Synechocystis strains A-Ut1, A-Ut2, A-Ut3 and A-Ut4 were grown in the presence of $10 \mathrm{mM}(1.50 \mathrm{~g} / \mathrm{L}) \mathrm{L}$-arabinose and $10 \mathrm{mM}(1.80 \mathrm{~g} / \mathrm{L}) \mathrm{D}$-glucose. a Photograph depicting differential growth shown by the transformant strains at the end of the third day of culture. $\mathbf{b}$ Dry biomass, $\mathbf{c}$ Residual arabinose and $\mathbf{d}$ Residual glucose measured in the cultures of the transformant strains. Data represented in graphs were collected from three biological replicates and presented as means \pm standard deviations

When grown under the mixotrophy-mixed sugar condition, the A-Ut3 strain showed arabinose consumption greater than the other A-Ut strains in accordance with the DW measurements. At the 7 th day of culture, the A-Ut3 strain showed $\sim 102 \%$ greater arabinose uptake than that by the A-Ut4 strain. Under mixotrophy, in the presence of arabinose alone as well as the mixed sugars, arabinose consumption exhibited by the A-Ut1 and A-Ut2 strains was found to be marginally lesser and similar to that by the A-Ut4 strain, respectively. The absence of two distinct growth phases and the simultaneous uptake of arabinose and glucose did not indicate diauxie in these strains, although glucose was consumed more efficiently than arabinose. (Fig. 5b-d; Additional File 1: Figure S1b, d, f, h). These results demonstrate that among the transporters under study, heterologous expression of only AraJ enhances arabinose transport in Synechocystis, which is further processed by the engineered isomerase catabolic pathway.

\section{Study of AraJ expression in AraE-possessing A-Ut strain Construction of recombinant strain A-Ut5}

To generate a strain co-expressing AraE and AraJ transporters, araJ was introduced into araE-possessing A-Ut1 strain. The resultant strain was denoted as A-Ut5 (Table 1). 


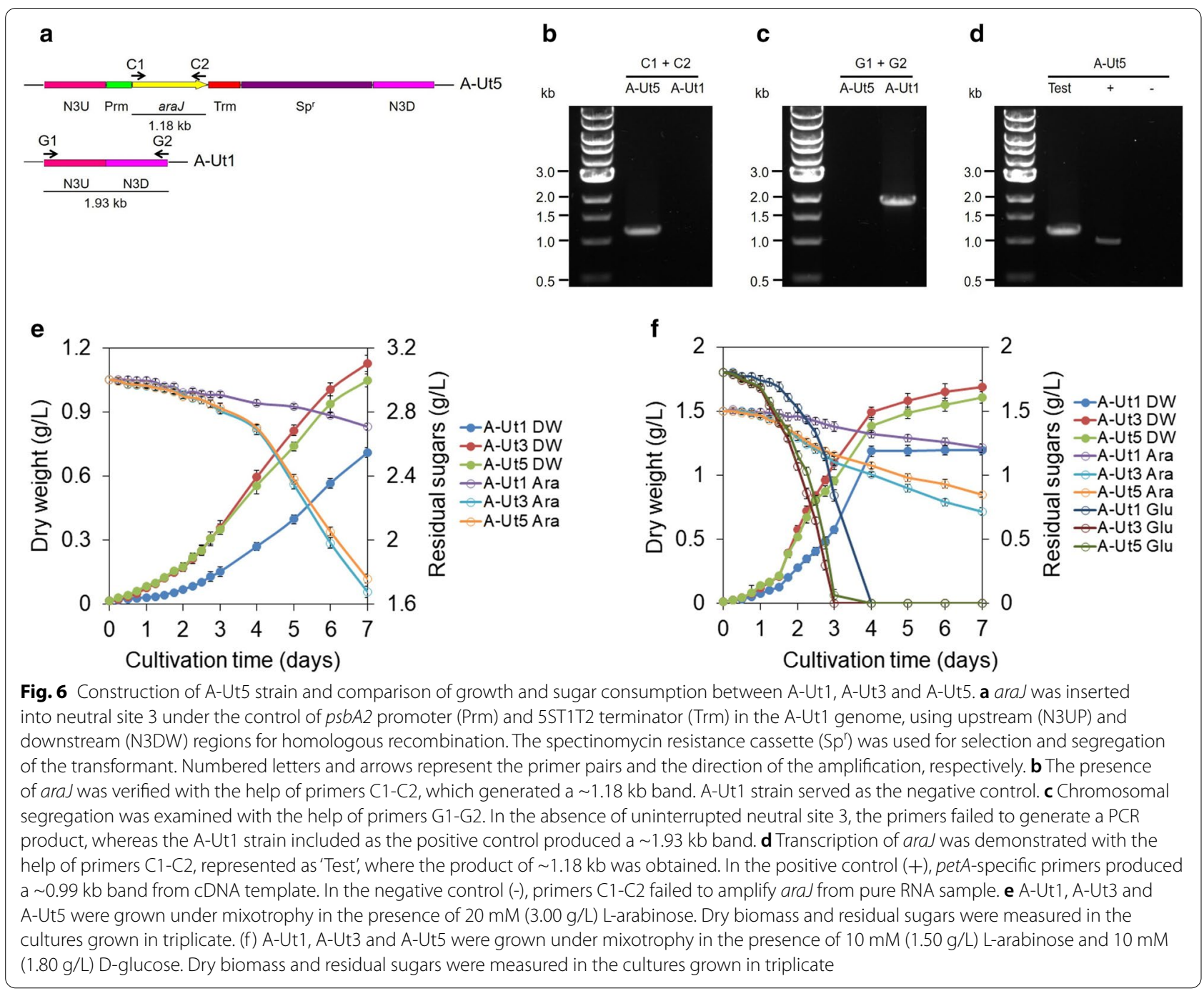

\section{Verification of genetic transformation and segregation of A-Ut5}

To verify the presence of araJ in the recombinant strain generated after the third round of transformation, araJspecific primers $\mathrm{C} 1 / \mathrm{C} 2$ were used. The primer pair generated approximately $1.18 \mathrm{~kb}$ PCR product (Fig. 6a, b). To verify segregation of the recombinant, the forward primer used to amplify the upstream region and the reverse primer used to amplify the downstream region of neutral site 3 were used (denoted here as G1/G2) (Ranade et al. 2015). Extension times in the PCR cycles were set just sufficient to amplify the uninterrupted neutral site 3. PCR amplifications produced a $~ 1.93$ $\mathrm{kb}$ band representing neutral site 3 only in the WT positive control. PCR did not generate any product in A-Ut5 indicating the absence of the uninterrupted neutral site and hence complete segregation of the recombinant strain (Fig. 6a, c).

\section{Verification of araJ transcription in A-Ut5}

After verification of segregation, transcription of araJ in the A-Ut5 strain was examined by RT-PCR as described above. In the presence of cDNA template obtained from the A-Ut5 strain, primers $\mathrm{C} 1 / \mathrm{C} 2$ for araJ generated the expected PCR product. Negative control reaction performed using pure RNA template and $\mathrm{C} 1 / \mathrm{C} 2$ primers failed to amplify araJ. Positive control reaction run using cDNA template showed amplification of petA (Fig. 6a, d). The results indicate successful araJ transcription and verify quality of the RNA sample.

\section{Study of biomass accumulation by A-Ut5}

To study the growth pattern exhibited by the A-Ut5 strain in comparison to the AraE-possessing A-Ut1 and AraJcarrying A-Ut3 strains, the strains were cultured under mixotrophy-arabinose and mixotrophy-mixed sugar conditions. Under both the growth conditions, A-Ut5 
showed higher biomass than A-Ut1, and comparable but marginally lower yields to those exhibited by the A-Ut3 strain. Under mixotrophy-arabinose, at day 7, the biomass obtained for A-Ut5 was $~ 48 \%$ greater than the biomass for A-Ut1, and 7\% lesser than that for the A-Ut3 strain. Under the mixotrophy-mixed sugar condition, at the 7th day of culture, A-Ut5 showed $\sim 34 \%$ greater and $\sim 5 \%$ lesser biomass than those obtained for the A-Ut1 and A-Ut3 strains, respectively (Fig. 6e, f).

\section{Study of sugar uptake by A-Ut5}

Sugar uptake measurements were made alongside the biomass estimations. Under mixotrophy-arabinose and mixotrophy-mixed sugar conditions, arabinose uptake by the A-Ut5 strain was greater than that by the A-Ut1 strain and comparable but marginally lower than that by the A-Ut3 strain. At the 7th day of culture, under mixotrophy-arabinose, the sugar uptake by the A-Ut5 strain was found to be $\sim 326 \%$ greater and $\sim 6 \%$ lesser than those exhibited by the A-Ut1 and A-Ut3 strains, respectively. Similarly, under the mixotrophy-mixed sugar condition, the arabinose consumption by the A-Ut5 strain was $\sim 126 \%$ greater and $\sim 16 \%$ lesser than the arabinose uptake by the A-Ut1 and A-Ut3 strains, respectively (Fig. 6e, f). The results demonstrate that the introduction of AraJ transporter was able to improve the performance of the A-Ut5 strain over its A-Ut1 parent.

\section{Discussion}

We have constructed and compared the abilities of Synechocystis strains to utilize the second most common pentose sugar, arabinose by the expression of heterologous genes. E. coli genes involved in the metabolism of arabinose have been used to metabolically engineer several other bacterial and yeast species (Mohagheghi et al. 2002; Deanda et al. 1996; Kawaguchi et al. 2008; Sasaki et al. 2009; Cao et al. 2017; Young et al. 2010; Zhang et al. 1998b). Hence, as in our previously reported xylose work (Ranade et al. 2015), E. coli was chosen as the source organism for the arabinose-specific genes, which were expressed under the control of a native light-dependent promoter, $p s b A 2$ (Mohamed and Jansson 1989; Lindberg et al; 2010). This promoter has been used for the expression of several heterologous genes (Zhou et al. 2014). Exclusion of E. coli-specific regulatory elements associated with the heterologous genes and the provision of continuous light exposure, ensured constant induction of psbA2 promoter.

Synechocystis lacks specialized arabinose transporters. However, as observed in the Synechocystis strains engineered to utilize xylose (Ranade et al. 2015), expression of the catabolic enzymes AraBAD alone was sufficient for the utilization of arabinose (Figs. $4 \mathrm{a}-\mathrm{c}$ and $5 \mathrm{a}-\mathrm{c}$;
Additional File 1: Figure S1h), indicating the involvement of endogenous sugar transporter/s. Therefore, arabinose uptake exhibited by the A-Ut strains possessing heterologous transporters pertained to the activities of both endogenous and heterologous transporters. MFS-type glucose transporter GlcP (also referred to as Gtr) is the lone characterized sugar transporter identified in Synechocystis so far (Pao et al. 1998; Zhang et al. 1998a). We have compared the arabinose-utilizing abilities of the engineered Synechocystis strains relying on the native sugar transporter/s with or without one of the three heterologous arabinose transporters. With this strategy, by studying DW accumulation and sugar uptake, we have attempted to compare the performance of the heterologous transporters when expressed individually in Synechocystis.

Our results have indirectly demonstrated the expression of the catabolic gene set at the protein level (Figs. 4a-c and 5a-c; Additional File 1: Figure S1b, d, f, $\mathrm{h}$ ), indicating that $E$. coli ribosomal binding sites (hereafter RBSs) of the araBAD operon were able to function in Synechocystis. We are unable to comment about the RBSs of the araFGH gene set at this time. Based on the biomass accumulation and the arabinose uptake results, AraFGHpossessing A-Ut2 strain failed to show any advantage over the A-Ut4 strain which lacked any non-native transporter (Figs. $4 \mathrm{a}-\mathrm{c}$ and $5 \mathrm{a}-\mathrm{c}$, Additional File 1: Figure S1d, h). Expression of only one of the three selected heterologous transporters was able to boost arabinose utilization in the corresponding transformant. Among the A-Ut strains, AraJ-possessing A-Ut3 strain showed the most remarkable results. A-Ut2 and A-Ut4 showed an intermediate ability to utilize arabinose and were found to be slightly more efficient than the A-Ut1 strain (Figs. 4a-c and 5a-c; Additional File 1: Figure S1b, d, f, h). We were unable to determine if AraFGH was functionally active, owing to its inability to improve the uptake of arabinose.

Under mixotrophy, in the presence of $20 \mathrm{mM}$ arabinose, and $10 \mathrm{mM}$ each of arabinose and glucose, A-Ut1 showed the lowest biomass yield and arabinose uptake among the A-Ut strains. Under mixotrophy-arabinose condition, A-Tr1 showed biomass yield comparable to that obtained under autotrophy. When compared to the other strains included in the study, A-Tr1 and A-Ut1 did not show any notable growth impairment under autotrophy and mixotrophy-glucose condition as well (Figs. $4 \mathrm{a}-\mathrm{c}$ and $5 \mathrm{a}-\mathrm{c}$; Additional File 1: Figure S1a-h). AraE and xylose transporter XylE show a high degree of homology with 141 identical amino acid residues, out of 472 and 491 amino acids, respectively (Maiden et al. 1987). XylE has recently been shown to function very efficiently in Synechocystis (Ranade et al. 2015). The performance of A-Ut1 strain could be due to one or more of the following factors, 
such as inability of AraBAD enzymes to efficiently process arabinose imported via AraE, stress caused by the expression of AraE and AraBAD at protein level and by the presence of L-arabinose. Accumulation of L-Ru5P, an L-arabinose pathway intermediate, has been known to exert harmful effects in E. coli cells (Englesberg et al. 1962). Insufficient strength of the RBSs in araBAD gene set could contribute to slower processing of L-Ru5P leading to slower growth of the A-Ut1 strain. However, in $S$. elongatus PCC 7942, expression of $E$. coli araE had failed to improve arabinose uptake (Cao et al. 2017). Hence, it is also possible that AraE may not be functionally active when expressed in Synechocystis.

E. coli ydeA has been shown to code for an MFS efflux transporter for L-arabinose and isopropylthio- $\beta$ galactoside (IPTG) (Carolé et al. 1999). With respect to cell growth, ydeA was found to be dispensable. Transcriptional activation of the gene was shown to lower intracellular concentration of arabinose which inhibits the expression of araBAD operon. Based on high homology between YdeA and AraJ, a role of AraJ in the export of non-metabolizable arabinose structural analogues was suggested (Bost et al. 1999). Earlier, AraJ was thought to be involved in the import or processing of arabinose polymers (Reeder and Schleif 1991). Similarly, with the help of a functional genomics tool, AraJ was grouped with other transporters such as B1657 (YdhP), YdeA, and YicM of E. coli, and YbcI, YdhL, YtbD, and YfhI of Bacillus subtilis, and their role in the transport of arabinose polymers was suggested (Lolkema and Slotboom 1998). However, the role of AraJ in the transport of arabinose polymers was deemed less likely, since none of the MFS proteins has been reported to transport substrates with molecular mass greater than 1,000 Da (Paulsen et al. 1998). 13 E. coli MFS transporters able to either import or export L-arabinose have been identified. Over-expression of a number of these transporter-coding genes including $y d e E$ showed various degrees of toxicity to the $E$. coli cells. It was suggested that, L-Ru5P toxicity may explain the need of arabinose efflux, and the efflux proteins may target intermediates of arabinose metabolism (Koita and Rao 2012). Based on the sequence analyses, AraJ has been suggested to be a multi-pass inner membrane protein, and its topological and transmembrane domains have been identified (The UniProt Consortium 2017).

In comparison to all other strains included in this study, under mixotrophy-glucose, AraJ-possessing A-Tr3 and A-Ut3 strains showed slower growth. Similarly, under mixotrophy-arabinose, A-Tr3 showed some degree of growth impairment. However, A-Tr3 and A-Ut3 did not show any significant differential growth under autotrophic conditions (Additional File 1: Figure S1a-h). The results could be related to those obtained by Koita and
Rao (2012) in E. coli, who had observed growth impairment due to over-expression of 5 out of 13 arabinoserelated transporters. Although Fritz et al. (2014) had found AraJ not being responsible for rapid off-switching of arabinose system in $E$. coli cells, there were indications of the involvement of AraJ in the efflux of L-arabinose. When grown in the presence of a range of arabinose concentrations, A-Ut3 was able to tolerate arabinose concentration as high as $160 \mathrm{mM}$, however maximum DW values were obtained in the presence of $60 \mathrm{mM}$ arabinose. In contrast, AraE-carrying A-Ut1 strain begins to show growth impairment even in the presence of $20 \mathrm{mM}$ arabinose (Fig. 4a, b; Additional File 1: Figures S1b, f and S2). The advantage of AraJ-possessing A-Ut3 strain suggests that the transport of L-arabinose mediated by AraJ is efficient, or sufficient for the AraBAD enzymes to process. It will be interesting to investigate whether AraJ also carries out the efflux of L-arabinose, and if it can serve as a safety valve to reduce metabolic stress in a heterologous platform. The possible role of AraJ in the efflux of L-arabinose is depicted in Fig. 1.

To study whether the introduction of AraJ transporter can improve the performance of AraE-possessing A-Ut1 strain, A-Ut5 strain was generated. Under mixotrophyarabinose and mixotrophy-mixed sugar conditions, the A-Ut5 strain showed higher DW and arabinose consumption than the A-Ut1 strain. The A-Ut5 strain's performance was comparable to that exhibited by the A-Ut3 strain (Fig. 6e, f). We speculated that one of the reasons for the inability of A-Ut5 to show greater DW and arabinose utilization than A-Ut3 could be limitations in the ability of the AraBAD enzymes to funnel L-arabinose into PPP. In an attempt to improve the catabolic activity of AraBAD by means of modifying RBSs, we created two modified araBAD gene sets by replacing the IR regions with a part of the native $p s b A 2$ promoter, CAAATACAT AAGGAATTATAACCAA and a $12 \mathrm{bp}$ long region of $E$. coli origin, AGGAGGTAATAT (Zurbriggen et al. 2012). Although a predictive design tool developed by Salis et al. (2009) had predicted advantage of the aforementioned RBSs over the original RBSs, the results indicated otherwise. The strains possessing both the modified gene sets showed decrease in DW yields (Additional File 1: Table S1, Fig. S3).

AraJ has been predicted to be a member of the drug $\mathrm{H}^{+}$antiporter (DHA1) family (Bost et al. 1999; Kanehisa et al. 2016). Proton-motive force-driven symporters and antiporters have been shown to behave like uniporters in the presence of a strong concentration gradient of their substrates (Zhang et al. 2015). Although the exact mechanisms of AraJ activities have not yet been experimentally demonstrated, based on predictive models for protein function, available literature and our results, it is 
a possibility that AraJ is a proton antiporter which carries out the uptake of L-arabinose by facilitated diffusion.

The ability of AraJ to function as an L-arabinose transporter can be exploited for biotechnological applications. The arabinose-utilizing strains, especially A-Ut3 can be modified further to enhance its ability to grow on arabinose. As discussed previously, several approaches such as codon optimization of the arabinose-specific genes, increasing the strength of RBSs, laboratory evolution, exploration of genomes of other bacteria and algae for potential arabinose-specific genes can be followed. The arabinose-utilizing strain/s can be further engineered to metabolize additional carbon sources, such as xylose, and to delete glycogen synthase gene/s, to allow availability of more carbon for biotechnological conversion (Ranade et al. 2015). To the best of our knowledge, we are among one of the first groups to express L-arabinose catabolic pathway in cyanobacteria, and to show the role of AraJ as an arabinose transporter. Another significance of the work lies in the functional expression of AraJ in Synechocystis, even prior to the determination of its function in the host organism.

\begin{abstract}
Abbreviations
ABC: ATP binding cassette; DW: Dry weight; D-Xu5P: D-xylulose-5-phosphate L-Ru5P: L-ribulose-5-phosphate; MFS: Major facilitator superfamily; RBS: Ribosomal binding sites; Synechocystis: Synechocystis sp. PCC 6803; WT: Wild-type strain; Mixotrophy-glucose: Mixotrophy with 20 mM glucose; Mixotrophyarabinose: Mixotrophy with 20 mM arabinose; Mixotrophy-mixed sugar: Mixotrophy with $10 \mathrm{mM}$ each of arabinose and glucose.
\end{abstract}

\section{Supplementary Information}

The online version contains supplementary material available at https://doi. org/10.1186/s13568-021-01277-7.

Additional file 1: Figure S1. Growth and sugar consumption by the arabinose-specific strains under various conditions. Synechocystis strains (a) A-Tr1, (b) A-Ut1, (c) A-Tr2, (d) A-Ut2, (e) A-Tr3, (f) A-Ut3, (g) WT and (h) A-Ut4 were grown as three biological replicates, and the data are presented as means \pm standard deviations. DW and residual sugars were estimated every 6 hours for the first 3 days followed by every 24 hours for the next 4 days. Blue line with filled squares, red lines with filled diamonds, light green line with filled triangles and violet line with filled circles represent growth under autotrophy, mixotrophy (20 mM arabinose), mixotrophy (20 mM glucose) and mixotrophy (10 mM each of arabinose and glucose) respectively. Similarly, light blue line with empty squares, orange line with empty circles and sky-blue line with crosses represent arabinose uptake under mixotrophy ( $20 \mathrm{mM}$ arabinose), arabinose uptake under mixotrophy (10 mM each of arabinose and glucose) and glucose uptake under mixotrophy (10 $\mathrm{mM}$ each of arabinose and glucose) respectively. BG-11 media with $20 \mathrm{mM}$ arabinose, $20 \mathrm{mM}$ glucose, $10 \mathrm{mM}$ arabinose and $10 \mathrm{mM}$ glucose contain 3.0026, 3.6032, 1.5013 and $1.8016 \mathrm{~g} / \mathrm{L}$ of the sugars respectively. Figure S2. Growth of A-Ut3 under various arabinose concentrations. A-Ut3 was grown in the presence of $0 \mathrm{mM}$ (autotrophy) to160 $\mathrm{mM}$ arabinose as three biological replicates, and the data are presented as means \pm standard deviations. DW was estimated every 24 hours for 7 days. Lines with filled circles represent growth in the presence of various arabinose concentrations, as specified within the figure. Figure
S3. Growth of Synechocystis strains under mixotrophy in the presence of $20 \mathrm{mM}$ arabinose. Synechocystis strains were grown in the presence of $20 \mathrm{mM}(3.0026 \mathrm{~g} / \mathrm{L}) \mathrm{L}$-arabinose. DW values estimated at the end of the seventh day are presented in the figure. Data were collected from three biological replicates and presented as means \pm standard deviations.

Table S1. Additional Synechocystis strains generated by modification of ribosome binding sites (RBSs) within araBAD gene set.

\section{Acknowledgements}

The authors thank Late Mrs. Renuka Ranade for her help with reviewing and editing the manuscript.

\section{Authors' contributions}

$\mathrm{SR}$ and $\mathrm{QH}$ conceived the research. SR designed and performed the experiments, analyzed the data, and prepared the manuscript. Both authors read and approved the final manuscript.

\section{Funding}

This research did not receive any specific grant from funding agencies in the public, commercial, or not-for-profit sectors. This publication was made possible by the Arkansas INBRE program, supported by a grant from the National Institute of General Medical Sciences, (NIGMS), P20 GM103429 from the National Institutes of Health. The first author used his personal funds to purchase kits for the estimation of L-arabinose and D-glucose.

\section{Availability of data and materials}

All data generated or analyzed during this study are included in this published article and the additional file. The Synechocystis strains generated in this study can be obtained from the corresponding author with discretion upon reasonable request.

\section{Declarations}

Ethics approval and consent to participate

This article does not contain any studies with human participants or animals performed by any of the authors.

\section{Consent for publication}

The authors give consent for the publication of the manuscript to the AMB express.

\section{Competing interests}

The authors declare that they have no knowledge of competing interests.

Received: 3 August 2021 Accepted: 6 August 2021

Published online: 13 August 2021

\section{References}

Bost S, Silva F, Belin D (1999) Transcriptional activation of ydeA, which encodes a member of the major facilitator superfamily, interferes with arabinose accumulation and induction of the Escherichia coli arabinose $P_{\text {BAD }}$ promoter. J Bacteriol 181:2185-2191. https://doi.org/10.1128/JB. 181.7.2185-2191.1999

Cao YQ, Li Q, Xia PF, Wei LJ, Guo N, Li JW, Wang SG (2017) AraBAD based toolkit for gene expression and metabolic robustness improvement in Synechococcus elongatus. Sci Rep 7:18059. https://doi.org/10.1038/ s41598-017-17035-4

Carolé S, Pichoff S, Bouché JP (1999) Escherichia coli gene ydeA encodes a major facilitator pump which exports L-arabinose and isopropyl- $\beta-D$ thiogalactopyranoside. J Bacteriol 181:5123-5125. https://doi.org/10. 1128/JB.181.16.5123-5125.1999

Caspi R, Billington R, Fulcher CA, Keseler IM, Kothari A, Krummenacker M, Latendresse M, Midford PE, Ong Q, Ong WK, Paley S, Subhraveti P, Karp PD (2018) The MetaCyc database of metabolic pathways and enzymes. Nucleic Acids Res 46:D633-D639. https://doi.org/10.1093/nar/gkx935 
Davies FK, Work VH, Beliaev AS, Posewitz MC (2014) Engineering limonene and bisabolene production in wild type and a glycogen-deficient mutant of Synechococcus sp. PCC 7002. Front Bioeng Biotechnol. https://doi.org/10.3389/fbioe.2014.00021

Deanda K, Zhang M, Eddy C, Picataggio S (1996) Development of an arabinose-fermenting Zymomonas mobilis strain by metabolic pathway engineering. Appl Environ Microbiol 62:4465-4470. https://doi.org/10. 1128/AEM.62.12.4465-4470.1996

Englesberg E, Anderson RL, Weinberg R, Lee N, Hoffee P, Huttenhauer G, Boyer H (1962) L-arabinose sensitive, L-ribulose 5-phosphate 4-epimerase-deficient mutants of Escherichia coli. J Bacteriol 84:137-146. https://doi.org/10.1128/JB.84.1.137-146.1962

Fritz G, Megerle JA, Westermayer SA, Brick D, Heermann R, Jung K, Rädler JO, Gerland U (2014) Single cell kinetics of phenotypic switching in the arabinose utilization system of E. coli. PLoS One 9:e89532. https://doi. org/10.1371/journal.pone.0089532

Gìrio FM, Fonseca C, Carvalheiro F, Duarte LC, Marques S, Bogel-Łukasik R (2010) Hemicelluloses for future ethanol: a review. Bioresour Technol 101:4775-4800. https://doi.org/10.1016/j.biortech.2010.01.088

Gonzalez-Esquer CR, Vermaas WF (2013) ClpB1 overproduction in Synechocystis sp. strain PCC 6803 increases tolerance to rapid heat shock. Appl Environ Microbiol 79:6220-6227. https://doi.org/10.1128/AEM. 01661-13

Jojima T, Omumasaba CA, Inui M, Yukawa HL (2010) Sugar transporters in efficient utilization of mixed sugar substrates: current knowledge and outlook. Appl Microbiol Biotechnol 85:471-480. https://doi.org/10.1007/ s00253-009-2292-1

Kanehisa M, Sato Y, Kawashima M, Furumichi M, Tanabe M (2016) KEGG as a reference resource for gene and protein annotation. Nucleic Acids Res 44:D457-D462. https://doi.org/10.1093/nar/gkv1070

Kawaguchi S, Sasaki M, Vertès AA, Inui M, Yukawa H (2008) Engineering of an L-arabinose metabolic pathway in Corynebacterium glutamicum. Appl Microbiol Biotechnol 77:1053-1062. https://doi.org/10.1007/ s00253-007-1244-x

Koita K, Rao CV (2012) Identification and analysis of the putative pentose sugar efflux transporters in Escherichia coli. PLoS One 7:e43700. https://doi.org/ 10.1371/journal.pone.0043700

Lindberg P, Park S, Melis A (2010) Engineering a platform for photosynthetic isoprene production in cyanobacteria, using Synechocystis as the model organism. Metab Eng 12:70-79. https://doi.org/10.1016/j.ymben.2009. 10.001

Lolkema JS, Slotboom DJ (1998) Hydropathy profile alignment: a tool to search for structural homologues of membrane proteins. FEMS Microbiol Rev 22:305-322. https://doi.org/10.1111/j.1574-6976.1998.tb00372.x

Lomascolo A, Uzan-Boukhris E, Sigoillot JC, Fine F (2012) Rapeseed and sunflower meal: a review on biotechnology status and challenges. Appl Microbiol Biotechnol 95:1105-1114. https://doi.org/10.1007/ s00253-012-4250-6

Maiden MC, Davis EO, Baldwin SA, Moore DC, Henderson PJ (1987) Mammalian and bacterial sugar transport proteins are homologous. Nature 325:641-643. https://doi.org/10.1038/325641a0

Mohagheghi A, Evans K, Chou YC, Zhang M (2002) Cofermentation of glucose, xylose and arabinose by genomic DNA-integrated xylose/arabinose fermenting strain of Zymomonas mobilis AX101. Appl Biochem Biotechnol 98:885-898. https://doi.org/10.1385/ABAB:98-100:1-9:885

Mohamed A, Jansson C (1989) Influence of light on accumulation of photosynthesis-specific transcripts in the cyanobacterium Synechocystis 6803. Plant Mol Biol 13:693-700. https://doi.org/10.1007/BF00016024

Pao SS, Paulsen IT, Saier MH Jr (1998) Major facilitator superfamily. Microbiol Mol Biol Rev 62:1-34. https://doi.org/10.1128/MMBR.62.1.1-34.1998

Paulsen IT, Sliwinski MK, Saier MH Jr (1998) Microbial genome analyses: global comparisons of transport capabilities based on phylogenies, bioenergetics and substrate specificities. J Mol Biol 277:573-592. https://doi.org/10. 1006/jmbi.1998.1609
Porter RD (1988) DNA Transformation. Methods Enzymol 167:703-712. https:// doi.org/10.1016/0076-6879(88)67081-9

Ragauskas AJ, Williams CK, Davison BH, Britovsek G, Cairney J, Eckert CA, Frederick WJ Jr, Hallett JP, Leak DJ, Liotta CL, Mielenz JR, Murphy R, Templer R, Tschaplinski T (2006) The path forward for biofuels and biomaterials. Science 311:484-489. https://doi.org/10.1126/science.1114736

Ranade S, Zhang Y, Kaplan M, Majeed W, He Q (2015) Metabolic engineering and comparative performance studies of Synechocystis sp. PCC 6803 strains for effective utilization of xylose. Front Microbiol. https://doi.org/ 10.3389/fmicb.2015.01484

Reeder T, Schleif R (1991) Mapping, sequence, and apparent lack of function of araJ, a gene of the Escherichia coli arabinose regulon. J Bacteriol 173:7765-7771. https://doi.org/10.1128/jb.173.24.7765-7771.1991

Saha BC (2003) Hemicellulose bioconversion. J Ind Microbiol Biotechnol 30:279-291. https://doi.org/10.1007/s10295-003-0049-x

Salis HM, Mirsky EA, Voigt CA (2009) Automated design of synthetic ribosome binding sites to control protein expression. Nat Biotechnol 27:946-950. https://doi.org/10.1038/nbt.1568

Sasaki M, Jojima T, Kawaguchi H, Inui M, Yukawa H (2009) Engineering of pentose transport in Corynebacterium glutamicum to improve simultaneous utilization of mixed sugars. Appl Microbiol Biotechnol 85:105-115. https://doi.org/10.1007/s00253-009-2065-x

Schädel C, Blöchl A, Richter A, Hoch G (2010) Quantification and monosachharide composition of hemicelluloses from different plant functional types. Plant Physiol Biochem 48:1-8. https://doi.org/10.1016/j.plaphy. 2009.09.008

Schleif R (2010) AraC protein, regulation of the L-arabinose operon in Escherichia coli, and the light switch mechanism of AraC action. FEMS Microbiol Rev 34:779-796. https://doi.org/10.1111/j.1574-6976.2010.00226.x

The UniProt Consortium (2017) UniProt: the universal protein knowledgebase. Nucleic Acids Res 45:D158-D169. https://doi.org/10.1093/nar/gkw1099

Yan X, Yu HJ, Hong Q, Li SP (2008) Cre/lox system and PCR-based genome engineering in Bacillus subtilis. Appl Environ Microbiol 74:5556-5562. https://doi.org/10.1128/AEM.01156-08

Young E, Lee SM, Alper $\mathrm{H}$ (2010) Optimizing pentose utilization in yeast: the need for novel tools and approaches. Biotechnol Biofuels 3:24. https:// doi.org/10.1186/1754-6834-3-24

Yu Y, You L, Liu D, Hollinshead W, Tang YJ, Zhang F (2013) Development of Synechocystis sp. PCC 6803 as a phototrophic cell factory. Mar Drugs 11:2894-2916. https://doi.org/10.3390/md11082894

Zhang CC, Jeanjean R, Joset F (1998) Obligate phototrophy in cyanobacteria: more than a lack of sugar transport. FEMS Microbiol Lett 161:285-292. https://doi.org/10.1111/j.1574-6968.1998.tb12959.x

Zhang M, Chou YC, Picataggio SK, Finkelstein M (1998b) Single Zymomonas mobilis strain for xylose and arabinose fermentation. US Patent 5,843,760.

Zhang XC, Zhao Y, Heng J, Jiang D (2015) Energy coupling mechanisms of MFS transporters. Protein Sci 24:1560-1579. https://doi.org/10.1002/pro.2759

Zhou J, Zhang H, Meng H, Zhu Y, Bao G, Zhang Y, Li Y, Ma Y (2014) Discovery of a super-strong promoter enables efficient production of heterologous proteins in cyanobacteria. Sci Rep 4:4500. https://doi.org/10.1038/srep0 4500

Zurbriggen A, Kirst H, Melis A (2012) Isoprene production via the mevalonic acid pathway in Escherichia coli (Bacteria). Bioenergy Res 5:814-828. https://doi.org/10.1007/s12155-012-9192-4

\section{Publisher's Note}

Springer Nature remains neutral with regard to jurisdictional claims in published maps and institutional affiliations. 